\title{
Environmental factors and progeny affecting milk yield and composition during the first lactation
}

\author{
J. Broucek ${ }^{1}$, S. Mihina, P. Kisac, A. Hanus, M. Uhrincat, V. Foltys, \\ S. Marencak and F. Benc
}

\author{
Research Institute of Animal Production \\ P.O. Box 30 c, 94992 Nitra, Slovakia
}

(Received 18 August 2004; revised version 7 March 2005; accepted 4 August 2005)

\begin{abstract}
The purpose of this study was to determine whether the milk yield (MY) of primiparous cows is affected by their housing to weaning, the method of providing liquid feed, sire (S) line, and season of birth and calving. Thirty-two heifer-calves were used in the experiment; 19 heifers were kept in individual housing (IH) and 13 in loose housing (LH) from the second day of life. On the seventh day the IH heifers were divided according to feeding milk replacer (MR) or milk: 10 were relocated from IH to a pen with a computer-controlled feeder (CCF) providing automatic feeding of MR $(\mathrm{AF}), 9$ heifers stayed in IH with bucket drinking (BF). The LH heifers were moved to a nursing cows pen (UF). Heifers were kept in free-stall housing after the first calving. The cows were also divided according to the sire, season of birth and calving. LH primiparous cows produced more milk throughout the first eight months of lactation, more MY, FCM and protein for $305 \mathrm{~d}$ lactation $(\mathrm{P}<0.05)$. UF cows had the highest MY throughout the first lactation and reached the significantly highest milk yield and FCM $(6894.1 ; 6541.9 \mathrm{~kg})$, whereas AF cows, the lowest $(5757.5 ; 5820.9 \mathrm{~kg}$; $\mathrm{P}<0.01$ ) for 305 days of lactation. The contents of fat and total solids (TS) were the highest in group AF. Sire lineages differed in the contents of fat, protein, lactose, non-fat solids (NSF), TS, and MY, lactose and NFS. Cows born and calved in the summer showed lower MY and FCM yields. The most productive cows were born and calved in the winter and spring.
\end{abstract}

KEY WORDS: heifers, rearing, housing, sire, calving season, cow performance

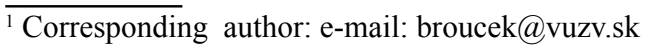




\section{INTRODUCTION}

Calves are usually separated from their mother during the first week of life and fed by milk replacer (MR). In Denmark, $86 \%$ of the calves are removed from their mother immediately after calving, $83 \%$ of the calves are placed in individual housing (IH) and $97 \%$ are fed milk from a bucket (Vaarst et al., 2001). Only about $10 \%$ of calves, particularly from small herds, are fed with native milk until weaning (Krohn et al., 1999). According to recent results from Swedish farms, $68 \%$ used IH during the milk-feeding period, $15 \%$ had calves in loose housing (LH) with bucket feeding and $13 \%$ housed the calves in LH with computer controlled feeder (CCF) (Svensson et al., 2000). Lack of movement in hutches (IH) can be adverse for calves. However, heifers reared in isolation until weaning gave significantly more milk than heifers from loose housing (Arave et al., 1985). According to Kaczor (2000), the housing system had no significant effect on the DWG of calves. Arave et al. (1992) found that pre-weaning isolation affected growth, but did not affect first lactation milk yield.

The early separation of the calf from the cow is of course important for maximum production, but this system can be disadvantageous for the calves. On the other hand, uncontrolled access to the mother by the calf can reduce the milk yield (MY) of the mother, but daily weight gains (DWG) of nursed calves are higher than of separated calves (Metz-Stefanowska, 1987; Khalili et al., 1992). Strzetelski et al. (2001) and Niwińska and Strzetelski (2004) reported better performance of calves fed by milk replacer more frequently. Bar-Peled et al. (1997) found that heifer calves reared by their own mother had better growth, earlier age at calving, and a tendency towards higher MY than calves fed MR.

Rearing of heifers is important for next performance, but other factors also influence milk yield after calving (Krzyżewski et al., 2004). DWG and milk yield are affected by several factors, including season (Tancin, 1991; Kaczor, 2000; Maltz et al., 2000) and ambient temperature in particular (Shearer and Beede, 1990; Knizkova et al., 2003).

These previous studies can provide some insight into the effects of housing, milk-feeding, sire lineage, season of birth and calving. However, they are inadequate as a basis for recommending environmental factors, as none of those studies examined how rearing of animals to weaning from milk or milk replacer can influence later adult production. Little research has been conducted to directly compare indicators of milk efficiency in dairy heifers reared in different individual housing and feeding designs.

This information is needed for educational programs and decision making by the industry and by dairy producers. Better knowledge of the effects of environmental conditions on milk yield are needed to better predict the effects of seasonal heat stress. 
The purpose of this study was to test the hypotheses that milk efficiency is impacted by the housing of heifers from the second to seventh day of life, themethod of feeding milk from the second week of life to weaning, the sire lineage, and season of birth and calving.

\section{MATERIAL AND METHODS}

Experimental design

Thirty-two Holstein heifer-calves were randomly divided in two housings on the second day of life (Table 1).

TABLE 1

Design of the experiment

$2^{\text {nd }}$ day

hutch

$n=19(\mathrm{IH})$
Total number of animals $n=32$

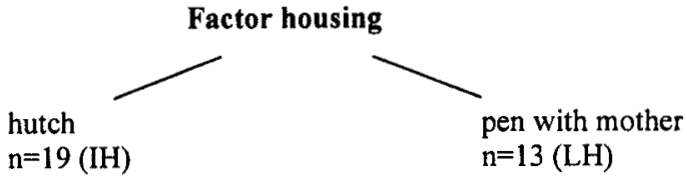

Total number of animals $n=32$

$7^{\text {th }}$ day

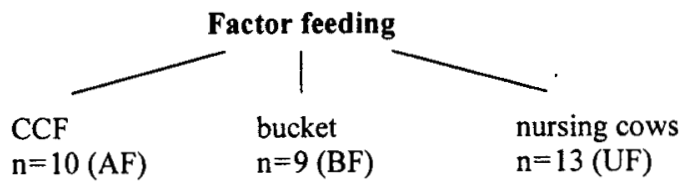

$56^{\text {th }}$ day

Weaning

after $305 \mathrm{~d}$ of lactation

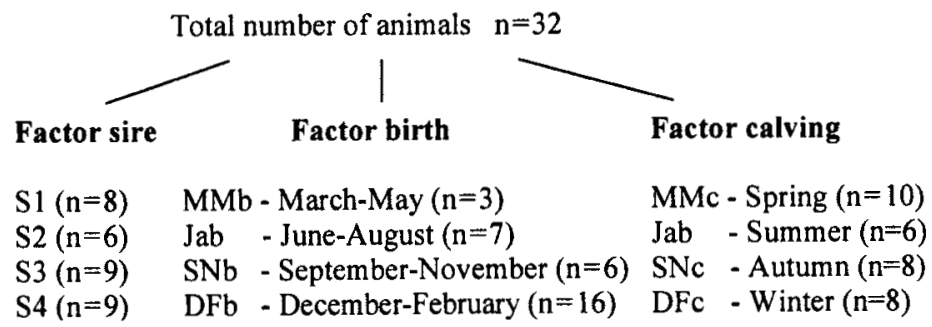


Calves of the AF treatment received $6 \mathrm{~kg}$ of MR per day divided into 4 portions in $6 \mathrm{~h}$ intervals (after the first three days, when they were made to drink MR). The amount of MR was increased from the $28^{\text {th }}$ day on to $8 \mathrm{~kg}$ per day. Calves of the BF treatment received the same amounts of MR divided into 2 portions in $12 \mathrm{~h}$ intervals. The source of protein in MR was powdered whey (Table 2).

TABLE 2

Composition of heifer diets as fed basis, $\mathrm{g} / 1 \mathrm{~kg}$

\begin{tabular}{lcccccccc}
\hline & $\mathrm{DM}^{1}$ & $\mathrm{CP}^{2}$ & $\mathrm{NEL}^{3}$ & $\mathrm{PDI}^{4}$ & Fat & Fibre & $\mathrm{Ca}$ & \multicolumn{1}{c}{$\mathrm{P}$} \\
\hline Native milk & 0.14 & 29.6 & 1.89 & 9.6 & 44.8 & 0 & 1.25 & 0.96 \\
Milk replacer & 0.94 & 206 & 12.1 & 82.7 & 166 & 6 & 9 & 7 \\
Starter mixture & 0.88 & 185 & 7.2 & 81.3 & 29 & 43 & 10 & 6 \\
Concentrate & 0.86 & 201 & 7.1 & 122 & 25.6 & 36 & 4.9 & 8.2 \\
TMR & 0.43 & 54.7 & 2.7 & 35.2 & 23.1 & 94.6 & 3.4 & 1.8 \\
\hline
\end{tabular}

${ }^{1}$ dry matter; ${ }^{2}$ crude protein; ${ }^{3}$ netto energy for lactation, $\mathrm{MJ} ;{ }^{4}$ protein digestible in small intestine

The number of calves of group UF per nursing cow was determined according to the cow's milk yield ( $6 \mathrm{~kg}$ milk per calf). A maximum of 3 cows were housed in one pen sized $8 \times 4.5 \mathrm{~m}$. Calves were allowed to suck ad libitum and they also had free access to the feeds of cows.

From the second day until weaning the calves could eat starter mixture and lucerne hay in free choice. The starter composition was, \%: extruded soyabean 21.48 , oats 16 , maize 41 , wheat 8.17 , wheat bran 3.44, dried lucerne meal 3.65, dried molasses 2.58 , protein-vitamin premix (Kalvicin, 2000) 2.81, mineral premix 0.87 .

All animals were weaned at the age of 8 weeks. Heifers of all groups were kept in common group pens in loose housing with bedding in age-balanced groups after weaning. They received $1.5 \mathrm{~kg}$ of concentrate mixture per day and lucerne hay in free choice from weaning to six months of age. From the age of 90 days they also received maize silage. From day 181, all heifers were fed according to Slovakian recommendations to attain $0.75 \mathrm{~kg}$ daily gain (Petrikovic and Sommer, 2002). The TMR composition (DM \%) represents: lucerne hay 17, lucerne haylage 32.1, maize silage 40.0, concentrate mixture 9 , and mineral/vitamin supplements 1 .

Heifers received a supplement of $1.5 \mathrm{~kg}$ of concentrate mixture per day until breeding, then $1 \mathrm{~kg}$ from the $5^{\text {th }}$ month of gestation, and this amount was gradually increased to $3 \mathrm{~kg}$ per day until calving. The concentrate mixture composition (DM \%) was: extruded soyabean meal 19.4, extruded rapeseed meal 11.0, wheat 29.5, wheat bran 4.9, maize 31.5 and mineral/vitamin premix 3.7. Equal conditions of nutrition were ensured in all groups.

Heifers were moved to the maternity barn three weeks before the expected date of calving. Primiparous dairy cows were kept in pens with free-stall housing with 
access to yards with concrete and fed by TMR twice a day according to the stages of lactation. TMR was balanced according to Slovakian nutrient requirements of dairy cattle (Petrikovic and Sommer, 2002) (Table 3).

TABLE 3

Composition of TTM diets for cows used in the experiment, $\mathrm{kg}$

\begin{tabular}{lccc}
\hline Indices & $1-4$ month & $5-7$ month & From 8. month \\
\hline Lucerne hay & 2 & 2.5 & 2 \\
Lucerne haylage & 8 & 7 & 8 \\
Concentrate mixture & 7.8 & 6.2 & 4.4 \\
Maize silage & 21 & 17 & 20 \\
Sugar-beet pulp & - & 10 & - \\
Wet brewer`s grain & 6 & 5 & 3 \\
Dry matter & 19.8 & 18.29 & 16.7 \\
MJ NE & 130 & 120.1 & 104.5 \\
PDI & 1.84 & 1.65 & 1.44 \\
Crude protein & 2.86 & 2.67 & 2.31 \\
Calculated milk efficiency & 32 & 27 & 20 \\
\hline
\end{tabular}

\section{Experimental techniques}

Milking was performed twice daily with a milking interval of $12 \mathrm{~h}$ in a $2 \times 5$ stall herringbone parlour, and individual MY was recorded once weekly (Tuesday evening, Wednesday morning) by Tru-tests. Proportional milk samples were collected every 2 weeks at the morning and afternoon milking and analysed by an infrared analyser. Milk was assayed for fat, protein, lactose, non-fat solids and total solids using infrared analysis (Milkoscan 133, Foss Electric, Hillerød, Denmark).

Heifers were first mated when they were at least 16 months old and when they reached about $360 \mathrm{~kg}$. Body condition score (1-5 points) (Jones, 1994) was used to evaluate the adequacy of the breeding-feeding program at the age of 15 months and $30^{\text {th }}$ day of lactation.

Reproduction and health were observed. BW on the $30^{\text {th }}$ day of lactation was $524.13 \pm 44.37 \mathrm{~kg}$. Breeding of cows during the first lactation began at $9 \mathrm{wk}$ postpartum.

\section{Statistical analyses}

The data were analysed with a statistical package STATISTIX, Version 2.0 (Anonymous, 1996). The normal distribution of data was evaluated by the WilkShapiro/Rankin Plot procedure. We found a non-normal distribution only in 
the somatic cell count. Therefore inter-group comparisons were tested by the Kruskal-Wallis ANOVA (factors: feeding, sire, season of birth and calving) and by the Mann-Whitney U test (factor: housing) in this parameter.

Data for milk yield and milk composition conformed to a normal distribution. Inter-group comparisons in each factor were analysed using a general linear model ANOVA (General AOV/AOCV). The dependent variables were milk production (including components), body weight, and daily gains and the independent variables were housing, feeding, sire, birth and calving season (treatment). The homogeneity of variance of the observed variables in groups, whose average values were being compared, was calculated by preliminary variance tests that determined whether the variabilities were equal. Bartlett's test for equality of variance tests was applied when sample sizes were not equal. The ratio of the largest intra-group variance over the smallest was also tested (Pearson and Hartley test). Significant differences among means were tested by Bonferroni's test. We chose Bonferroni's method from Multiple Comparison Procedures since the number of heifers in groups was unequal (Snedecor and Cochran, 1989). This test is generally more conservative than the others in the statistics packet.

The interactions between observed factors (housing, feeding, sire, birth and calving) were also computed using two-way ANOVA with the interactions model:

$$
\mathrm{Y}_{i j k}=\mu+\alpha_{i}+\beta_{j}+\gamma_{i j}+\varepsilon_{i j k}
$$

where $\mathrm{Y}_{i j k}$ is a dependent variable, $\mu$ is the overall mean, $\alpha_{i}$ is the effect of factor A on the level $\mathrm{i}, \beta_{j}$ is the effect of factor B on the level $\mathrm{j}, \gamma_{i j}$ is the interaction between factor $\mathrm{A}$ on the level $\mathrm{i}$ and factor B on the level $\mathrm{j}$, and $\varepsilon_{i j k}$ is the residual error.

The results given in the text are expressed as means $\pm \mathrm{SD}$.

\section{RESULTS}

\section{Housing}

The heifers of group LH had a higher BW at weaning at 56 days than heifers from group IH $(80.28 \pm 8.99$ vs $67.89 \pm 12.01 \mathrm{~kg} ; \mathrm{P}<0.01)$ and higher $\mathrm{DWG}$ from birth to weaning $(0.68 \pm 0.16$ vs $0.47 \pm 0.19 \mathrm{~kg} ; \mathrm{P}<0.01)$. Age at calving was not significantly different between groups.

LH cows had a higher MY throughout the first eight months of lactation (Figure 1). The greatest and highly significant difference was in the fifth month of lactation $(780.5 \pm 132.2 \mathrm{~kg}$ vs $636.9 \pm 128.4 \mathrm{~kg} ; \mathrm{P}<0.01)$. As we can see in Figure 
2, except in the ninth month, LH cows always produced more FCM in comparison with the IH cows. However, a significant effect of this factor was obvious only in the fifth month (710.1 $\pm 102.3 \mathrm{~kg}$ vs $588.6 \pm 96.8 \mathrm{~kg} ; \mathrm{P}<0.05)$.

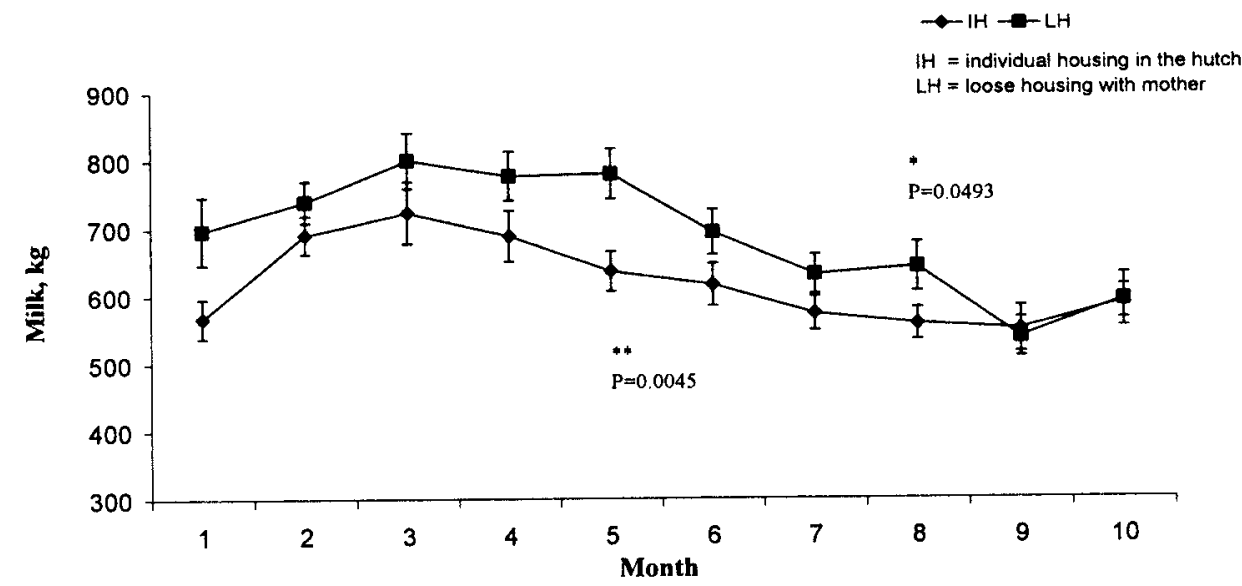

Figure 1. Milk yield according to the housing of calves from $2^{\text {nd }}$ to $7^{\text {th }}$ day of life (means $\pm \mathrm{SE}$ )

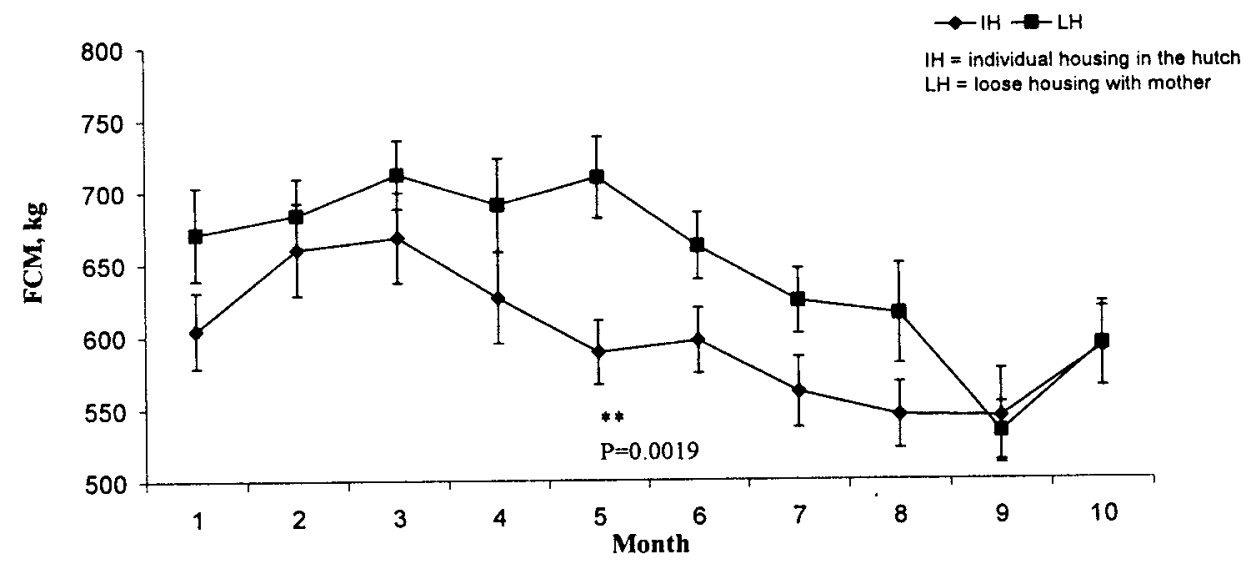

Figure 2. FCM according to the housing of calves from $2^{\text {nd }}$ to $7^{\text {th }}$ day of life (means $\pm \mathrm{SE}$ )

The MY in the 305 days of lactation (Table 4) was also higher in LH cows than in the IH group $(\mathrm{P}<0.05)$. Significant differences were also found in the productions of FCM $(\mathrm{P}<0.05)$ and protein $(\mathrm{P}<0.05)$. 
The average score at 15 months of age was $3.12 \pm 0.42$ and $2.6 \pm 0.48$ on the $30^{\text {th }}$ day of lactation.

TABLE 4 Effect of of housing from the second to seventh day of life on growth and 305 days milk production

\begin{tabular}{|c|c|c|c|c|c|c|}
\hline Indices & Group & $\mathrm{n}$ & Mean & $\mathrm{SD}^{1}$ & $\mathrm{SE}^{2}$ & $\mathrm{~F} / \mathrm{P}^{3}$ \\
\hline \multirow[t]{2}{*}{$\mathrm{BW}$ at the $56 \mathrm{~d}, \mathrm{~kg}$} & $\mathrm{IH}$ & 19 & 67.89 & 12.01 & 2.75 & 9.94 \\
\hline & LH & 13 & 80.28 & 8.99 & 2.49 & $0.0037^{* *}$ \\
\hline \multirow{2}{*}{$\begin{array}{l}\text { DWG from birth to } \\
56 \mathrm{~d}, \mathrm{~kg}\end{array}$} & $\mathrm{IH}$ & 19 & 0.47 & 0.19 & 0.04 & 9.70 \\
\hline & LH & 13 & 0.68 & 0.16 & 0.05 & $0.0040^{* *}$ \\
\hline \multirow[t]{2}{*}{ Milk, kg } & $\mathrm{IH}$ & 19 & 6202.10 & 923.99 & 211.98 & 4.50 \\
\hline & LH & 13 & 6894.10 & 879.78 & 244.01 & $0.0423^{*}$ \\
\hline \multirow[t]{2}{*}{ FCM, kg } & $\mathrm{IH}$ & 19 & 5986.4 & 669.20 & 153.53 & 5.45 \\
\hline & LH & 13 & 6541.9 & 649.16 & 180.04 & $0.0265^{*}$ \\
\hline \multirow[t]{2}{*}{ Protein, kg } & IH & 19 & 193.22 & 27.35 & 6.27 & 5.56 \\
\hline & LH & 13 & 215.32 & 23.91 & 6.63 & $0.0250^{*}$ \\
\hline
\end{tabular}

${ }^{1}$ standard deviation of the mean; ${ }^{2}$ standard error of the mean; ${ }^{3} \mathrm{~F}$-value/P-value

$* \mathrm{P}<0.05 ; * * \mathrm{P}<0.01$

\section{Feeding of milk}

BW at weaning was the highest in UF heifers and the lowest in AF heifers $(\mathrm{P}<0.001)$. Similarly, DWG during the milk-feeding period was also the highest in UF heifers $(\mathrm{P}<0.001)$ (Table 5).

UF cows had the highest MY throughout the first lactation. BF cows yielded more only in the third, ninth and tenth months (Figure 3). The lowest milk efficiency in all months was recorded in group AF. A significant difference was found between groups UF and AF in the sixth month $(694.1 \pm 120.2 \mathrm{~kg}$ vs $560.4 \pm 116.4 \mathrm{~kg}, \mathrm{P}<0.05)$. Highly significant differences were found in the fifth month, when group UF milked $780.5 \pm 132.2 \mathrm{~kg}$, group BF $729.9 \pm 93.5 \mathrm{~kg}$ and group AF only $553.3 \pm 93.7 \mathrm{~kg}(\mathrm{P}<0.01)$.

Except in the second, third, ninth and tenth months of lactation, production of FCM was always the highest in group UF (Figure 4). In contrast, the animals of group AF fed by the CCF had the lowest production. A highly significant difference was found in the fifth $(710.1 \pm 102.3 \mathrm{~kg}$ vs $547.2 \pm 94.7 \mathrm{~kg} ; \mathrm{P}<0.01)$ and sixth months $(662.2 \pm 84.2 \mathrm{~kg}$ vs $561.3 \pm 95.1 \mathrm{~kg} ; \mathrm{P}<0.05)$. 
TABLE 5

Effect of feeding milk from the second week of life to weaning on growth and 305 days milk production

\begin{tabular}{|c|c|c|c|c|c|c|}
\hline Indices & Group & $\mathrm{n}$ & Mean & $\mathrm{SD}^{1}$ & $\mathrm{SE}^{2}$ & $\mathrm{~F} / \mathrm{P}^{3}$ \\
\hline \multirow[t]{3}{*}{$\mathrm{BW}$ at the $56 \mathrm{~d}, \mathrm{~kg}$} & $\mathrm{AF}$ & 10 & 61.96 & 9.34 & 2.95 & 9.88 \\
\hline & $\mathrm{BF}$ & 9 & 74.49 & 11.57 & 3.86 & $0.0005^{* * *}$ \\
\hline & UF & 13 & 80.28 & 8.99 & 2.49 & UF:AF ${ }^{* * *} ; \mathrm{BF}: \mathrm{AF}^{*}$ \\
\hline \multirow{3}{*}{$\begin{array}{l}\text { DWG from birth to } \\
56 \mathrm{~d}, \mathrm{~kg}\end{array}$} & $\mathrm{AF}$ & 10 & 0.36 & 0.10 & 0.03 & 11.48 \\
\hline & $\mathrm{BF}$ & 9 & 0.59 & 0.21 & 0.07 & $0.0002^{* * *}$ \\
\hline & UF & 13 & 0.68 & 0.16 & 0.05 & $\mathrm{UF}: \mathrm{AF}^{* * *} ; \mathrm{BF}: \mathrm{AF}^{* *}$ \\
\hline \multirow{3}{*}{$\begin{array}{c}\mathrm{BW} \text { at the } 30 \mathrm{~d} \text { of } \\
\text { lactation, } \mathrm{kg}\end{array}$} & $\mathrm{AD}$ & 10 & 504.8 & 36.49 & 11.54 & 1.96 \\
\hline & $\mathrm{BD}$ & 9 & 521.89 & 32.85 & 10.95 & 0.1586 \\
\hline & UD & 13 & 540.54 & 52.56 & 14.58 & N.S. \\
\hline \multirow[t]{6}{*}{ Milk, kg } & $\mathrm{AF}$ & 10 & 5757.5 & 865.5 & 273.70 & 5.57 \\
\hline & $\mathrm{BF}$ & 9 & 6696.1 & 746.0 & 248.68 & $0.0090^{* *}$ \\
\hline & UF & 13 & 6894.1 & 879.8 & 244.01 & $\mathrm{UF}: \mathrm{AF}^{* *}$ \\
\hline & $\mathrm{AF}$ & 10 & 5820.9 & 797.3 & 252.12 & 3.42 \\
\hline & $\mathrm{BF}$ & 9 & 6170.3 & 469.3 & 156.43 & $0.0463^{*}$ \\
\hline & UF & 13 & 6541.9 & 649.2 & 180.04 & UF:AF* \\
\hline \multirow[t]{3}{*}{ Fat, \% } & $\mathrm{AF}$ & 10 & 4.10 & 0.40 & 0.13 & 3.61 \\
\hline & $\mathrm{BF}$ & 9 & 3.57 & 0.55 & 0.18 & $0.0399^{*}$ \\
\hline & UF & 13 & 3.75 & 0.37 & 0.10 & $\mathrm{AF}: \mathrm{BF}^{*}$ \\
\hline \multirow[t]{3}{*}{ Protein, $\mathrm{kg}$} & $\mathrm{AF}$ & 10 & 180.9 & 27.5 & 8.68 & 5.93 \\
\hline & $\mathrm{BF}$ & 9 & 206.9 & 20.7 & 6.92 & $0.0069^{* *}$ \\
\hline & UF & 13 & 215.3 & 23.9 & 6.63 & $\mathrm{UF}: \mathrm{AF}^{* *}$ \\
\hline \multirow[t]{3}{*}{ Lactose, $\mathrm{kg}$} & $\mathrm{AF}$ & 10 & 285.0 & 40.6 & 12.83 & 5.78 \\
\hline & $\mathrm{BF}$ & 9 & 340.0 & 40.8 & 13.60 & $0.0077^{* *}$ \\
\hline & UF & 13 & 342.9 & 47.7 & 13.24 & UF,BF:AF* \\
\hline \multirow[t]{3}{*}{ Non fat solids, $\mathrm{kg}$} & $\mathrm{AF}$ & 10 & 515.3 & 67.5 & 21.35 & 5.33 \\
\hline & $\mathrm{BF}$ & 9 & 599.9 & 68.7 & 22.91 & $0.0107^{*}$ \\
\hline & UF & 13 & 608.9 & 78.4 & 21.74 & UF:AF* \\
\hline \multirow[t]{3}{*}{ Total solids, $\%$} & $\mathrm{AF}$ & 10 & 13.14 & 0.74 & 0.23 & 3.96 \\
\hline & $\mathrm{BF}$ & 9 & 12.56 & 0.59 & 0.19 & $0.0302 *$ \\
\hline & UF & 13 & 12.41 & 0.57 & 0.16 & AF:UF* \\
\hline \multirow[t]{3}{*}{ Total solids, $\mathrm{kg}$} & $\mathrm{AF}$ & 10 & 749.8 & 95.5 & 30.20 & 3.74 \\
\hline & $\mathrm{BF}$ & 9 & 832.9 & 74.1 & 24.71 & $0.0359 *$ \\
\hline & UF & 13 & 846.5 & 90.9 & 25.23 & UF:AF* \\
\hline
\end{tabular}

${ }^{1}$ standard deviation of the mean; ${ }^{2}$ standard error of the mean; ${ }^{3} \mathrm{~F}$-value $/ \mathrm{P}$-value $* \mathrm{P}<0.05 ; * * \mathrm{P}<0.01 ; * * * \mathrm{P}<0.001$ 


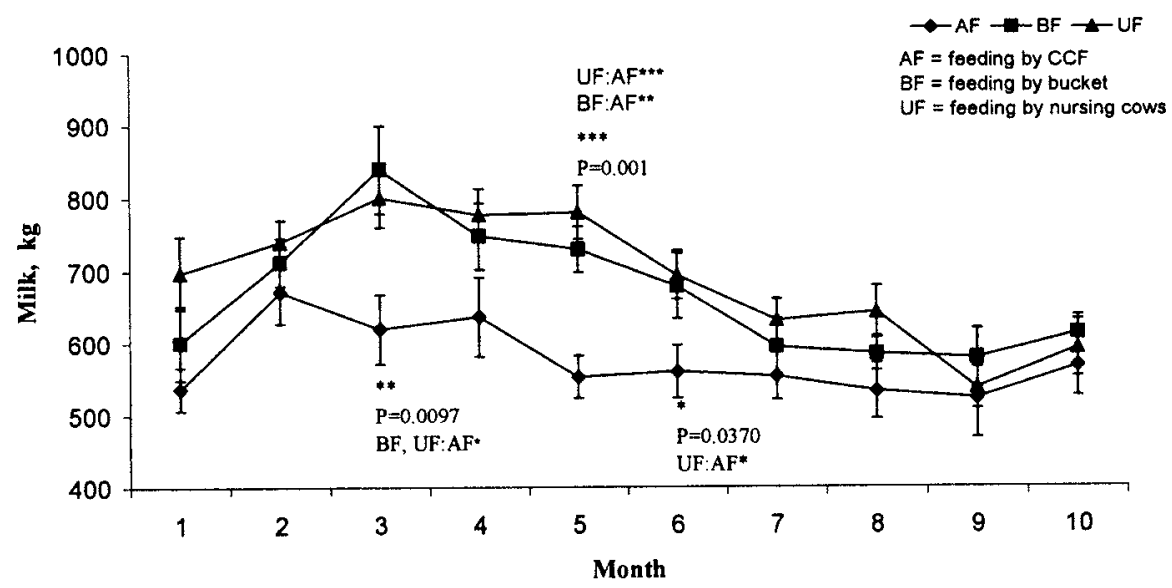

Figure 3. Milk yield according to the method of milk feeding of calves (means $\pm \mathrm{SE}$ )

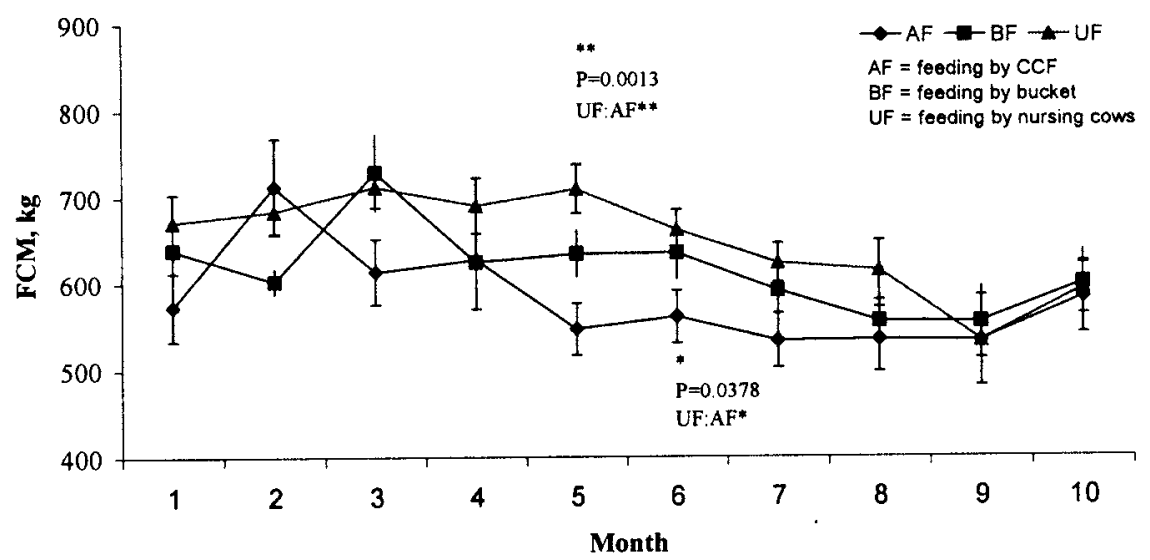

Figure 4. FCM according to the method of milk feeding of calves (means $\pm \mathrm{SE}$ )

The UF cows reached the highest MY, and AF cows, the lowest $(\mathrm{P}<0.01)$ for 305 days of lactation (Table 5). A similar trend was also recorded in FCM $(\mathrm{P}<0.05)$. The contents of fat and TS were the highest in the AF group (4.10 and $13.14 \%$, respectively).

Sire

Heifers after four observed sires differed in $\mathrm{BW}$ at birth $(\mathrm{P}<0.05)$ (Table 6). The daughters of $\mathrm{S}_{3}$ reached the highest MY except in the seventh and eighth months 
(Figure 5). Significant differences $(\mathrm{P}<0.05)$ were found in the fifth $(799.2 \pm 157.9$ $\mathrm{kg}$ vs $602.1 \pm 113.4 \mathrm{~kg}$ ) and sixth months $(756.4 \pm 118.1 \mathrm{~kg}$ vs $590.8 \pm 100.8 \mathrm{~kg})$, always between $\mathrm{S}_{3}$ and $\mathrm{S}_{1}$. For no month of lactation did we find a significant difference among daughters in FCM.

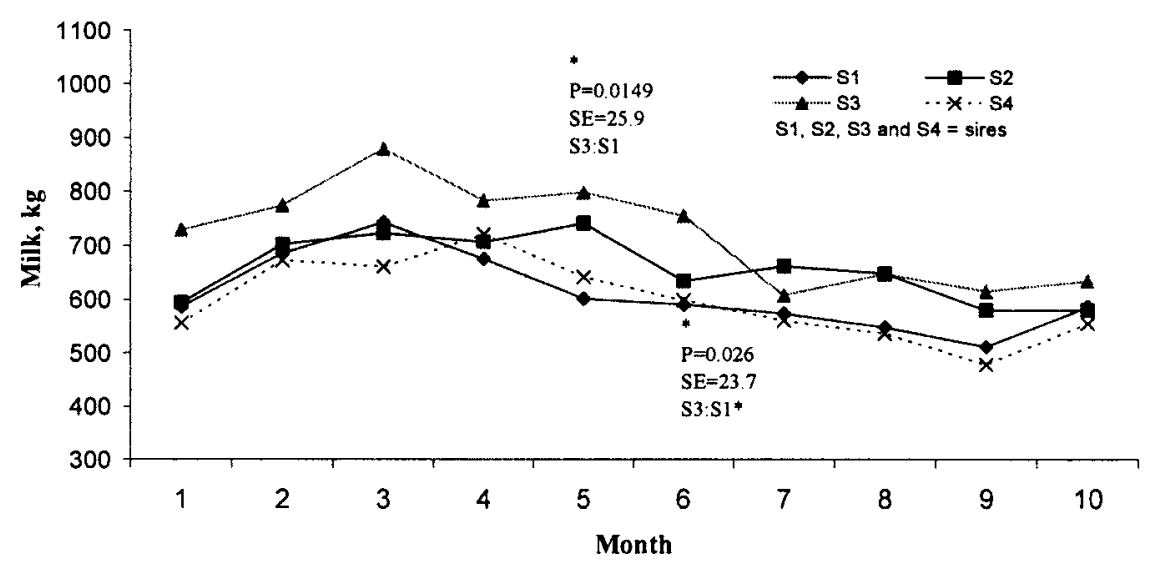

Figure 5. Milk yield according to the sire line

The effects of sire lineage were very significant in fat content $(\mathrm{P}<0.001)$, production of lactose, and TS content $(\mathrm{P}<0.01)$ over 305 days of lactation. Statistical significance $(\mathrm{P}<0.05)$ was shown in $\mathrm{MY}$, protein and lactose contents, as well as in the content and production of NFS (Table 6).

\section{Season of birth}

The highest BW at weaning and $180^{\text {th }}$ day of life and the lowest BW were found in $\mathrm{DFb}$ and $\mathrm{JAb}$ cows (Table 7). JAb cows showed the lowest MY during almost all months of lactation. In contrast, DFb cows had the highest milk production. Highly significant differences $(\mathrm{P}<0.01)$ among seasons were found in the second $(\mathrm{SNb} 793.1 \pm 127.0 \mathrm{~kg}$ and $\mathrm{DFb} 742.6 \pm 96.6 \mathrm{~kg}$ vs JAb $586.5 \pm 68.0 \mathrm{~kg})$ and fifth (DFb $769.3 \pm 127.3 \mathrm{~kg}$ vs JAb $542.6 \pm 103.6 \mathrm{~kg}$ ) months of lactation (Figure 6). Significant differences $(\mathrm{P}<0.05)$ were found in the third (DFb 837.2 \pm 160.7 $\mathrm{kg}$ vs JAb $619.0 \pm 185.8 \mathrm{~kg}$ ) and fourth months (DFb 774.8 $\pm 122.1 \mathrm{~kg}$ vs JAb $575.6 \pm 173.3 \mathrm{~kg})$. 
TABLE 6

Effect of the sire on growth and 305 days milk performance

\begin{tabular}{|c|c|c|c|c|c|c|}
\hline Indices & Group & $\mathrm{n}$ & Mean & $\mathrm{SD}^{1}$ & $\mathrm{SE}^{2}$ & $\mathrm{~F} / \mathrm{P}^{3}$ \\
\hline \multirow[t]{4}{*}{ BW at the birth, $\mathrm{kg}$} & $\mathrm{S}_{1}$ & 8 & 39.87 & 4.73 & 1.67 & 3.63 \\
\hline & $\mathrm{S}_{2}$ & 6 & 44.67 & 4.84 & 1.98 & $0.0248^{*}$ \\
\hline & $\mathrm{S}_{3}^{2}$ & 9 & 39.00 & 1.80 & 0.60 & \\
\hline & $\mathrm{S}_{4}$ & 9 & 43.89 & 4.78 & 1.59 & \\
\hline \multirow[t]{4}{*}{ Milk, kg } & $\mathrm{S}_{1}$ & 8 & 6098.8 & 929.80 & 328.73 & 4.21 \\
\hline & $\mathrm{S}_{2}$ & 6 & 6579.3 & 920.24 & 375.68 & $0.0141^{*}$ \\
\hline & $\mathrm{S}_{3}^{2}$ & 9 & 7255.8 & 879.76 & 293.25 & $\mathrm{~S}_{3}: \mathrm{S}_{1,4}{ }^{*}$ \\
\hline & $\mathrm{S}_{4}$ & 9 & 5988.3 & 618.42 & 206.14 & \\
\hline \multirow[t]{4}{*}{ Fat, $\%$} & $\mathrm{~S}_{1}$ & 8 & 3.97 & 0.42 & 0.15 & 7.34 \\
\hline & $\mathrm{S}_{2}$ & 6 & 4.11 & 0.29 & 0.11 & $0.0009^{* * *}$ \\
\hline & $\mathrm{S}_{3}^{2}$ & 9 & 3.33 & 0.40 & 0.13 & $\mathrm{~S}_{214}: \mathrm{S}_{3}^{* *}$ \\
\hline & $\mathrm{S}_{4}$ & 9 & 3.96 & 0.33 & 0.11 & \\
\hline \multirow[t]{4}{*}{ Protein, \% } & $\mathrm{S}_{1}$ & 8 & 3.13 & 0.14 & 0.05 & 3.61 \\
\hline & $\mathrm{S}_{2}$ & 6 & 3.06 & 0.11 & 0.05 & $0.0255^{*}$ \\
\hline & $\mathrm{S}_{3}$ & 9 & 3.08 & 0.08 & 0.03 & $\mathrm{~S}_{4}: \mathrm{S}_{2}{ }^{*}$ \\
\hline & $\mathrm{S}_{4}$ & 9 & 3.24 & 0.14 & 0.04 & \\
\hline \multirow[t]{4}{*}{ Lactose, \% } & $\mathrm{S}_{1}$ & 8 & 4.99 & 0.09 & 0.03 & 2.94 \\
\hline & $\mathrm{S}_{2}$ & 6 & 4.91 & 0.07 & 0.03 & $0.0499^{*}$ \\
\hline & $\mathrm{S}_{3}$ & 9 & 5.07 & 0.05 & 0.02 & $\mathrm{~S}_{3}: \mathrm{S}_{2}{ }^{*}$ \\
\hline & $\mathrm{S}_{4}$ & 9 & 5.00 & 0.14 & 0.05 & \\
\hline \multirow[t]{4}{*}{ Lactose, $\mathrm{kg}$} & $\mathrm{S}_{1}$ & 8 & 305.10 & 47.61 & 16.83 & 4.82 \\
\hline & $\mathrm{S}_{2}$ & 6 & 318.32 & 37.81 & 15.44 & $0.0079^{* *}$ \\
\hline & $\mathrm{S}_{3}$ & 9 & 368.85 & 48.55 & 16.18 & $\mathrm{~S}_{3}: \mathrm{S}_{1,4}{ }^{*}$ \\
\hline & $\mathrm{S}_{4}$ & 9 & 299.78 & 34.14 & 11.38 & \\
\hline \multirow[t]{4}{*}{ Non fat solids, $\%$} & $\mathrm{~S}_{1}$ & 8 & 9.01 & 0.27 & 0.09 & 4.28 \\
\hline & $\mathrm{S}_{2}$ & 6 & 8.62 & 0.25 & 0.10 & $0.0131^{*}$ \\
\hline & $\mathrm{S}_{3}$ & 9 & 8.89 & 0.19 & 0.06 & $\mathrm{~S}_{4,1}: \mathrm{S}_{2}{ }^{*}$ \\
\hline & $\mathrm{S}_{4}$ & 9 & 9.02 & 0.21 & 0.07 & \\
\hline \multirow[t]{4}{*}{ Non fat solids, $\mathrm{kg}$} & $\mathrm{S}_{1}$ & 8 & 552.87 & 76.41 & 27.01 & 3.57 \\
\hline & $\mathrm{S}_{2}$ & 6 & 565.02 & 72.03 & 29.41 & $0.0264^{*}$ \\
\hline & $\mathrm{S}_{3}$ & 9 & 643.74 & 83.77 & 27.92 & $\mathrm{~S}_{3}: \mathrm{S}_{4}^{*}$ \\
\hline & $\mathrm{S}_{4}$ & 9 & 540.25 & 59.11 & 19.70 & \\
\hline \multirow[t]{4}{*}{ Total solids, \% } & $\mathrm{S}_{1}$ & 8 & 13.11 & 0.80 & 0.28 & 5.44 \\
\hline & $\mathrm{S}_{2}$ & 6 & 12.61 & 0.63 & 0.26 & $0.0045^{* *}$ \\
\hline & $\mathrm{S}_{3}$ & 9 & 12.07 & 0.43 & 0.14 & $\mathrm{~S}_{1}: \mathrm{S}_{3}^{* *}$ \\
\hline & $\mathrm{S}_{4}$ & 9 & 12.94 & 0.42 & 0.14 & $\mathrm{~S}_{4}: \mathrm{S}_{3}{ }^{*}$ \\
\hline
\end{tabular}

${ }^{1}$ standard deviation of the mean; ${ }^{2}$ standard error of the mean; ${ }^{3} \mathrm{~F}$-value/P-value $* \mathrm{P}<0.05 ; * * \mathrm{P}<0.01 ; * * * \mathrm{P}<0.001$ 


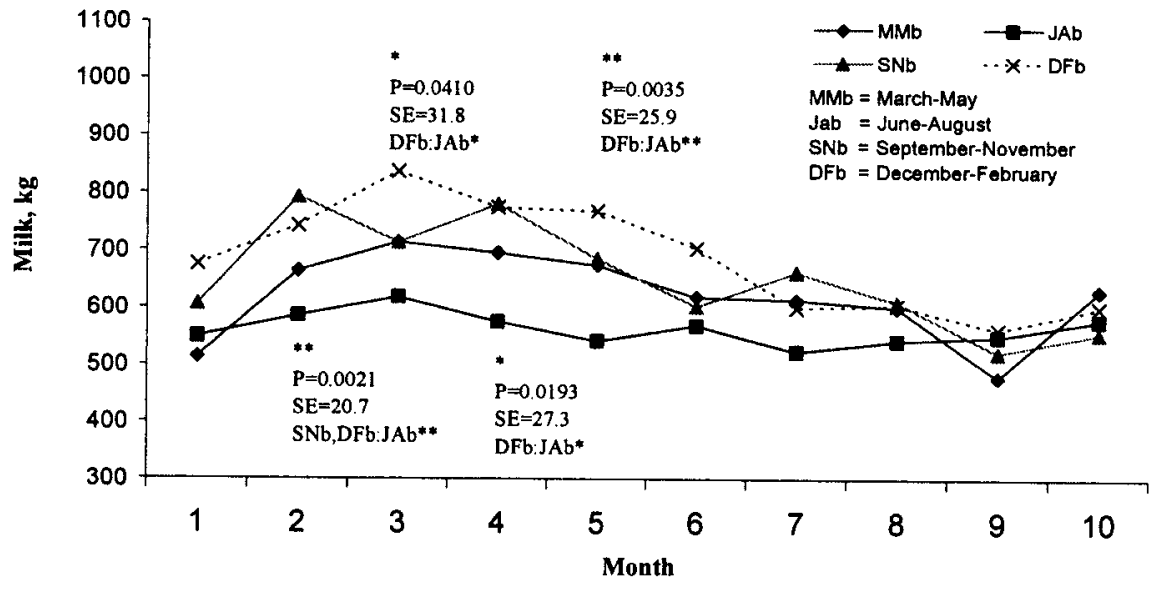

Figure 6. Milk yield according to the season at the birth

TABLE 7

Effect of season of birth on growth and 305 days milk performance

\begin{tabular}{|c|c|c|c|c|c|c|}
\hline Indices & Group & $\mathrm{n}$ & Mean & SD & SE & $\mathrm{F} / \mathrm{P}^{3}$ \\
\hline \multirow[t]{4}{*}{$\mathrm{BW}$ at the $56 \mathrm{~d}, \mathrm{~kg}$} & $\mathrm{MM}_{\mathrm{b}}$ & 3 & 76.70 & 13.87 & 8.01 & 8.84 \\
\hline & $\mathrm{JA}_{\mathrm{b}}{ }^{\mathrm{b}}$ & 7 & 59.24 & 10.41 & 3.93 & $0.0003^{* * *}$ \\
\hline & $\mathrm{SN}_{b}^{\circ}$ & 6 & 67.98 & 6.06 & 2.47 & $\mathrm{DF}_{\mathrm{b}}: \mathrm{JA}_{\mathrm{b}}^{* * *}$ \\
\hline & $\mathrm{DF}_{\mathrm{b}}^{0}$ & 16 & 80.05 & 9.03 & 2.26 & \\
\hline \multirow[t]{4}{*}{$\mathrm{BW}$ at the $180 \mathrm{~d}, \mathrm{~kg}$} & MM & 3 & 184.93 & 33.48 & 19.33 & 7.24 \\
\hline & $\mathrm{JA}_{\mathrm{b}}{ }^{\mathrm{B}}$ & 7 & 152.04 & 13.08 & 4.94 & $0.0010^{* *}$ \\
\hline & $\mathrm{SN}_{b}^{\circ}$ & 6 & 157.72 & 15.83 & 6.46 & $\mathrm{DF}_{\mathrm{b}}: \mathrm{JA}_{\mathrm{b}}^{* *}$ \\
\hline & $\mathrm{DF}_{\mathrm{b}}^{\mathrm{b}}$ & 16 & 186.13 & 18.89 & 4.72 & $\mathrm{DF}_{\mathrm{b}}^{\mathrm{b}}: \mathrm{SN}_{\mathrm{b}}{ }^{*}$ \\
\hline \multirow{4}{*}{$\begin{array}{l}\text { DWG from birth to } \\
56 \mathrm{~d}, \mathrm{~kg}\end{array}$} & $\mathrm{MM}_{\mathrm{b}}$ & 3 & 0.66 & 0.26 & 0.15 & 15.84 \\
\hline & $\mathrm{JA}_{\mathrm{b}}$ & 7 & 0.29 & 0.09 & 0.03 & $0.0000^{* * *}$ \\
\hline & $\mathrm{SN}_{\mathrm{b}}$ & 6 & 0.45 & 0.06 & 0.03 & $\mathrm{DF}_{\mathrm{b}}: \mathrm{JA}_{\mathrm{b}}^{* * *}$ \\
\hline & $\mathrm{DF}_{\mathrm{b}}$ & 16 & 0.69 & 0.14 & 0.03 & $\mathrm{MM}_{\mathrm{b}}^{0}: \mathrm{JA}_{\mathrm{b}}^{* * *}$ \\
\hline \multirow{4}{*}{$\begin{array}{l}\text { DWG from birth to } \\
180 \mathrm{~d}, \mathrm{~kg}\end{array}$} & $\mathrm{MM}_{\mathrm{b}}$ & 3 & 0.81 & 0.19 & 0.11 & 8.85 \\
\hline & $\mathrm{JA}_{\mathrm{b}}{ }^{\circ}$ & 7 & 0.60 & 0.07 & 0.02 & $0.0003^{* * *}$ \\
\hline & $\mathrm{SN}_{\mathrm{b}}^{\circ}$ & 6 & 0.63 & 0.09 & 0.03 & $\mathrm{DF}_{\mathrm{b}}: \mathrm{JA}_{\mathrm{b}}^{* * *}$ \\
\hline & $\mathrm{DF}_{\mathrm{b}}$ & 16 & 0.80 & 0.09 & 0.02 & $\begin{array}{l}\mathrm{DF}_{\mathrm{b}}: \mathrm{SN}_{\mathrm{b}}^{* *} \\
\mathrm{JA}_{\mathrm{b}}: \mathrm{MM}_{\mathrm{b}}^{*}\end{array}$ \\
\hline \multirow{4}{*}{$\begin{array}{l}\mathrm{BW} \text { at the } 30 \mathrm{~d} \text { of } \\
\text { lactation, } \mathrm{kg}\end{array}$} & $\mathrm{MM}_{\mathrm{b}}$ & 3 & 586.67 & 56.86 & 32.83 & 6.44 \\
\hline & $\mathrm{JA}_{\mathrm{b}}$ & 7 & 496.86 & 30.58 & 11.56 & $0.0019^{* *}$ \\
\hline & $\mathrm{SN}_{b}$ & 6 & 493.17 & 25.85 & 10.55 & $\mathrm{MM}_{\mathrm{b}}: \mathrm{JA}_{\mathrm{b}}, \mathrm{SN}_{\mathrm{b}}{ }^{* *}$ \\
\hline & $\mathrm{DF}_{\mathrm{b}}$ & 16 & 535.94 & 37.15 & 9.29 & \\
\hline \multirow[t]{4}{*}{ Milk, kg } & $\mathrm{MM}_{\mathrm{b}}$ & 3 & 6211.0 & 703.51 & 406.17 & 3.53 \\
\hline & $\mathrm{JA}_{\mathrm{b}}{ }^{\circ}$ & 7 & 5639.7 & 1047.2 & 395.79 & $0.0277^{*}$ \\
\hline & $\mathrm{SN}_{\mathrm{b}}$ & 6 & 6538.8 & 746.25 & 304.65 & $\mathrm{DF}_{\mathrm{b}}: \mathrm{JA}_{\mathrm{b}}^{*}$ \\
\hline & $\mathrm{DF}_{\mathrm{b}}$ & 16 & 6882.5 & 825.67 & 206.42 & \\
\hline
\end{tabular}


TABLE 7 continued

\begin{tabular}{|c|c|c|c|c|c|c|}
\hline Indices & Group & $\mathrm{n}$ & Mean & SD & SE & $\mathrm{F} / \mathrm{P}^{3}$ \\
\hline FCM, kg & $\begin{array}{l}\mathrm{MM}_{\mathrm{b}} \\
\mathrm{JA}_{\mathrm{b}} \\
\mathrm{SN}_{\mathrm{b}} \\
\mathrm{DF}_{\mathrm{b}}\end{array}$ & $\begin{array}{r}3 \\
7 \\
6 \\
16\end{array}$ & $\begin{array}{l}6108.1 \\
5563.5 \\
6668.1 \\
6344.2\end{array}$ & $\begin{array}{l}480.57 \\
843.45 \\
623.17 \\
536.90\end{array}$ & $\begin{array}{l}277.46 \\
318.80 \\
254.41 \\
134.22\end{array}$ & $\begin{array}{l}3.82 \\
0.0206^{*} \\
\mathrm{SN}_{\mathrm{b}}: \mathrm{JA}_{\mathrm{b}}{ }^{*}\end{array}$ \\
\hline Fat, \% & $\begin{array}{l}\mathrm{MM}_{\mathrm{b}} \\
\mathrm{JA}_{\mathrm{b}} \\
\mathrm{SN}_{\mathrm{b}} \\
\mathrm{DF}_{\mathrm{b}}\end{array}$ & $\begin{array}{r}3 \\
7 \\
6 \\
16\end{array}$ & $\begin{array}{l}3.93 \\
3.96 \\
4.17 \\
3.59\end{array}$ & $\begin{array}{l}0.55 \\
0.37 \\
0.28 \\
0.47\end{array}$ & $\begin{array}{l}0.32 \\
0.14 \\
0.11 \\
0.12\end{array}$ & $\begin{array}{l}3.14 \\
0.0407^{*}\end{array}$ \\
\hline Fat, kg & $\begin{array}{l}\mathrm{MM}_{\mathrm{b}} \\
\mathrm{JA}_{\mathrm{b}} \\
\mathrm{SN}_{\mathrm{b}} \\
\mathrm{DF}_{\mathrm{b}}\end{array}$ & $\begin{array}{r}3 \\
7 \\
6 \\
16\end{array}$ & $\begin{array}{l}241.58 \\
220.51 \\
270.17 \\
239.41\end{array}$ & $\begin{array}{l}23.83 \\
30.07 \\
23.74 \\
26.85\end{array}$ & $\begin{array}{r}13.76 \\
11.37 \\
9.69 \\
6.71\end{array}$ & $\begin{array}{l}3.74 \\
0.0224^{*} \\
\mathrm{SN}_{\mathrm{b}}: \mathrm{JA}_{\mathrm{b}}{ }^{*}\end{array}$ \\
\hline Protein, kg & $\begin{array}{l}\mathrm{MM}_{\mathrm{b}} \\
\mathrm{JA}_{\mathrm{b}} \\
\mathrm{SN}_{\mathrm{b}} \\
\mathrm{DF}_{\mathrm{b}}\end{array}$ & $\begin{array}{r}3 \\
7 \\
6 \\
16\end{array}$ & $\begin{array}{l}198.83 \\
173.51 \\
201.56 \\
215.63\end{array}$ & $\begin{array}{l}23.79 \\
32.19 \\
13.74 \\
21.78\end{array}$ & $\begin{array}{r}13.73 \\
12.17 \\
5.61 \\
5.44\end{array}$ & $\begin{array}{l}5.26 \\
0.0053^{* *} \\
\mathrm{DF}_{\mathrm{b}}: \mathrm{JA}_{\mathrm{b}}^{* *}\end{array}$ \\
\hline Lactose, \% & $\begin{array}{l}\mathrm{MM}_{\mathrm{b}} \\
\mathrm{JA}_{\mathrm{b}} \\
\mathrm{SN}_{\mathrm{b}} \\
\mathrm{DF}_{\mathrm{b}}\end{array}$ & $\begin{array}{r}3 \\
7 \\
6 \\
16\end{array}$ & $\begin{array}{l}5.12 \\
4.93 \\
4.91 \\
5.04\end{array}$ & $\begin{array}{l}0.12 \\
0.09 \\
0.08 \\
0.08\end{array}$ & $\begin{array}{l}0.07 \\
0.03 \\
0.03 \\
0.02\end{array}$ & $\begin{array}{l}6.83 \\
0.0013^{* *} \\
\mathrm{MM}_{\mathrm{b}} \mathrm{DF}_{\mathrm{b}} \\
\mathrm{JA}_{\mathrm{b}}, \mathrm{SN}_{\mathrm{b}}{ }^{\mathrm{b}}\end{array}$ \\
\hline Lactose, $\mathrm{kg}$ & $\begin{array}{l}\mathrm{MM}_{\mathrm{b}} \\
\mathrm{JA}_{\mathrm{b}} \\
\mathrm{SN}_{\mathrm{b}} \\
\mathrm{DF}_{\mathrm{b}}\end{array}$ & $\begin{array}{r}3 \\
7 \\
6 \\
16\end{array}$ & $\begin{array}{l}318.65 \\
277.91 \\
316.62 \\
347.96\end{array}$ & $\begin{array}{l}35.53 \\
49.05 \\
27.21 \\
46.55\end{array}$ & $\begin{array}{l}20.51 \\
18.54 \\
11.11 \\
11.64\end{array}$ & $\begin{array}{l}4.29 \\
0.0130^{*} \\
\mathrm{DF}_{\mathrm{b}}: \mathrm{JA}_{\mathrm{b}}{ }^{*}\end{array}$ \\
\hline Non fat solids, $\mathrm{kg}$ & $\begin{array}{l}\mathrm{MM}_{\mathrm{b}} \\
\mathrm{JA}_{\mathrm{b}} \\
\mathrm{SN}_{\mathrm{b}} \\
\mathrm{DF}_{\mathrm{b}}\end{array}$ & $\begin{array}{r}3 \\
7 \\
6 \\
16\end{array}$ & $\begin{array}{l}561.48 \\
499.93 \\
568.52 \\
617.12\end{array}$ & $\begin{array}{l}64.73 \\
82.22 \\
50.09 \\
72.43\end{array}$ & $\begin{array}{l}37.37 \\
31.08 \\
20.45 \\
18.11\end{array}$ & $\begin{array}{l}4.56 \\
0.0101^{*} \\
\mathrm{DF}_{\mathrm{b}}: \mathrm{JA}_{\mathrm{b}}{ }^{*}\end{array}$ \\
\hline Total solids, $\mathrm{kg}$ & $\begin{array}{l}\mathrm{MM}_{\mathrm{b}} \\
\mathrm{JA}_{\mathrm{b}} \\
\mathrm{SN}_{\mathrm{b}} \\
\mathrm{DF}_{\mathrm{b}}\end{array}$ & $\begin{array}{r}3 \\
7 \\
6 \\
16\end{array}$ & $\begin{array}{l}800.29 \\
720.44 \\
827.25 \\
849.50\end{array}$ & $\begin{array}{r}67.84 \\
108.68 \\
52.86 \\
84.24\end{array}$ & $\begin{array}{l}39.17 \\
41.08 \\
21.58 \\
21.06\end{array}$ & $\begin{array}{l}3.86 \\
0.0198^{*} \\
\mathrm{DF}_{\mathrm{b}}: \mathrm{JA}_{\mathrm{b}}{ }^{*}\end{array}$ \\
\hline
\end{tabular}

${ }^{1}$ standard deviation of the mean; ${ }^{2}$ standard error of the mean; ${ }^{3} \mathrm{~F}$-value/P-value $* \mathrm{P}<0.05 ; * * \mathrm{P}<0.01 ; * * * \mathrm{P}<0.001$

Except for the ninth month, the lowest FCM was recorded in JAb cows. The greatest absolute difference at the level of $218.4 \mathrm{~kg}$ was in the fourth month of lactation ( $\mathrm{SNb} 767.6 \pm 113.7 \mathrm{~kg}$ vs JAb 549.2 $\pm 158.3 ; \mathrm{P}<0.05)$. There were differences between $\mathrm{SNb}(790.8 \pm 172.4 \mathrm{~kg})$ and $\mathrm{JAb}(612.6 \pm 61.4 \mathrm{~kg})$ in the second month and between $\mathrm{DFb}(678.3 \pm 108.2 \mathrm{~kg})$ and $\mathrm{JAb}(524.7 \pm 87.7 \mathrm{~kg})$ in the fifth month.

In the assessment of 305 days lactation (Table 7), DFb cows showed the highest MY, protein, lactose, NFS and TS and JAb cows the lowest $(\mathrm{P}<0.05)$. 
Production of FCM and fat was the highest in the $\mathrm{SNb}$ group and the lowest again in the $\mathrm{JAb}$ group $(\mathrm{P}<0.05)$.

Season of calving

Negative effects of the summer period were again found in the evaluation by season of calving. SNc heifers had the lowest BW at the 180th day of life and DWG from birth to 6 months (Table 8). Comparison with MMc heifers gave significant differences $(\mathrm{P}<0.05)$. JAc cows showed the lowest MY in the third, fourth, sixth, seventh and ninth months of lactation. The most productive were DFc and MMc cows. A very high difference $(\mathrm{P}<0.001)$ was found in the third month (DFc 874.7 $\pm 106.6 \mathrm{~kg}$ and MMc $845.0 \pm 169.8 \mathrm{~kg}$ vs JAc $563.1 \pm 133.6$ $\mathrm{kg}, \mathrm{P}<0.01$; DFc $874.7 \pm 106.6 \mathrm{~kg}$ vs SNc $666.4 \pm 116.6 \mathrm{~kg})$. Other significant

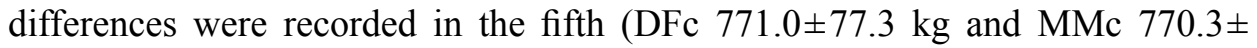
$161.3 \mathrm{~kg}$ vs SNc $581.6 \pm 76.9 \mathrm{~kg}$ ) and the sixth (DFc 715.9 $\pm 105.5 \mathrm{~kg}$ and MMc $713.9 \pm 126.9$ vs JAc $517.8 \pm 88.7 \mathrm{~kg}$ ) months.

Cows calving in the summer showed lower FCM. The most notable, very highly significant difference was recorded in the sixth month $(\mathrm{P}<0.001)$. Animals Animals calving in the winter and spring produced highly significantly more FCM in comparison with animals calving in the summer (DFc $686.4 \pm 82.8 \mathrm{~kg}$ and MMc $664.3 \pm 64.6 \mathrm{~kg}$ vs JAc $513.9 \pm 78.8 \mathrm{~kg} ; \mathrm{P}<0.01)$. Other significant differences were observed in the third (DFc $768.6 \pm 88.4 \mathrm{~kg}$ vs JAc $594.4 \pm 141.8 \mathrm{~kg} ; \mathrm{P}<0.05$ ) and

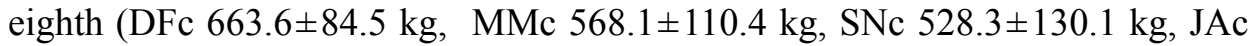
$520.7 \pm 70.7 \mathrm{~kg} ; \mathrm{P}<0.05)$ months of lactation.

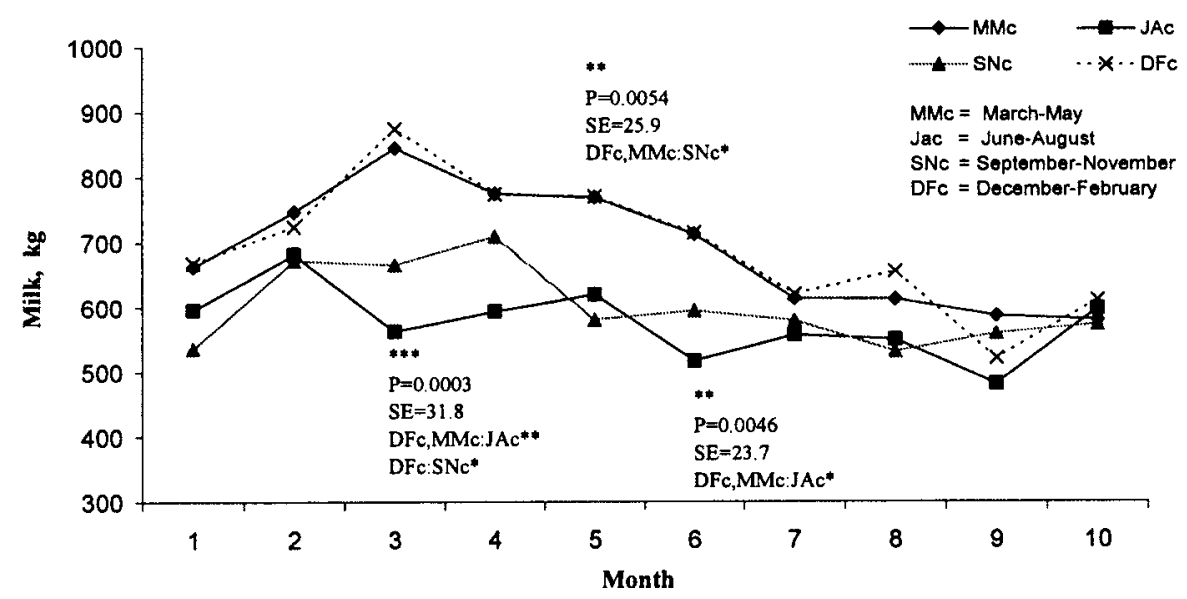

Figure 7. Milk yield according to the season at the calving 
TABLE 8

Effect of season of calving on growth and 305 days milk performance

\begin{tabular}{|c|c|c|c|c|c|c|}
\hline Indices & Group & $\mathrm{n}$ & Mean & $\mathrm{SD}^{1}$ & $\mathrm{SE}^{2}$ & $\mathrm{~F} / \mathrm{P}^{3}$ \\
\hline $\begin{array}{l}\text { BW at the } 180 \\
\text { d, kg }\end{array}$ & $\begin{array}{l}\mathrm{MM}_{\mathrm{c}} \\
\mathrm{JA}_{\mathrm{c}} \\
\mathrm{SN}_{\mathrm{c}} \\
\mathrm{DF}_{\mathrm{c}}\end{array}$ & $\begin{array}{r}10 \\
6 \\
8 \\
8\end{array}$ & $\begin{array}{l}186.49 \\
164.88 \\
153.31 \\
182.85\end{array}$ & $\begin{array}{l}16.98 \\
14.88 \\
16.15 \\
29.07\end{array}$ & $\begin{array}{r}5.37 \\
6.07 \\
5.71 \\
10.28\end{array}$ & $\begin{array}{l}4.97 \\
0.0069^{* *} \\
\mathrm{MM}_{\mathrm{c},} \mathrm{DF}_{\mathrm{c}}: \mathrm{SN}_{\mathrm{c}}^{*}\end{array}$ \\
\hline $\begin{array}{l}\text { DWG from birth } \\
\text { to } 180 \mathrm{~d}, \mathrm{~kg}\end{array}$ & $\begin{array}{l}\mathrm{MM}_{\mathrm{c}} \\
\mathrm{JA}_{\mathrm{c}} \\
\mathrm{SN}_{\mathrm{c}} \\
\mathrm{DF}_{\mathrm{c}}\end{array}$ & $\begin{array}{r}10 \\
6 \\
8 \\
8\end{array}$ & $\begin{array}{l}0.81 \\
0.69 \\
0.62 \\
0.77\end{array}$ & $\begin{array}{l}0.09 \\
0.09 \\
0.08 \\
0.16\end{array}$ & $\begin{array}{l}0.03 \\
0.04 \\
0.03 \\
0.06\end{array}$ & $\begin{array}{l}4.49 \\
0.0108^{*} \\
\mathrm{MM}_{\mathrm{c}}: \mathrm{SN}_{\mathrm{c}}{ }^{*}\end{array}$ \\
\hline Milk, kg & $\begin{array}{l}\mathrm{MM}_{\mathrm{c}} \\
\mathrm{JA}_{\mathrm{c}} \\
\mathrm{SN}_{\mathrm{c}} \\
\mathrm{DF}_{\mathrm{c}}\end{array}$ & $\begin{array}{r}10 \\
6 \\
8 \\
8\end{array}$ & $\begin{array}{l}6924.9 \\
5764.4 \\
6011.1 \\
6942.5\end{array}$ & $\begin{array}{l}987.62 \\
948.45 \\
809.11 \\
530.64\end{array}$ & $\begin{array}{l}312.31 \\
387.20 \\
286.06 \\
187.61\end{array}$ & $\begin{array}{l}4.01 \\
0.0171^{*}\end{array}$ \\
\hline Fat, $\%$ & $\begin{array}{l}\mathrm{MM}_{\mathrm{c}} \\
\mathrm{JA}_{\mathrm{c}} \\
\mathrm{SN}_{\mathrm{c}} \\
\mathrm{DF}_{\mathrm{c}}\end{array}$ & $\begin{array}{r}10 \\
6 \\
8 \\
8\end{array}$ & $\begin{array}{l}3.48 \\
4.09 \\
4.01 \\
3.81\end{array}$ & $\begin{array}{l}0.44 \\
0.31 \\
0.45 \\
0.44\end{array}$ & $\begin{array}{l}0.14 \\
0.13 \\
0.16 \\
0.15\end{array}$ & $\begin{array}{l}3.44 \\
0.0300^{*}\end{array}$ \\
\hline Protein, kg & $\begin{array}{l}\mathrm{MM}_{\mathrm{c}} \\
\mathrm{JA}_{\mathrm{c}} \\
\mathrm{SN}_{\mathrm{c}} \\
\mathrm{DF}_{\mathrm{c}}\end{array}$ & $\begin{array}{r}10 \\
6 \\
8 \\
8\end{array}$ & $\begin{array}{l}213.16 \\
178.67 \\
189.46 \\
218.90\end{array}$ & $\begin{array}{l}25.41 \\
32.56 \\
23.07 \\
13.11\end{array}$ & $\begin{array}{r}8.03 \\
13.29 \\
8.16 \\
4.63\end{array}$ & $\begin{array}{l}4.69 \\
0.0090^{* *} \\
\mathrm{DF}_{\mathrm{c}}: \mathrm{JA}_{\mathrm{c}}^{*}\end{array}$ \\
\hline Lactose, $\%$ & $\begin{array}{l}\mathrm{MM}_{\mathrm{c}} \\
\mathrm{JA}_{\mathrm{c}} \\
\mathrm{SN}_{\mathrm{c}} \\
\mathrm{DF}_{\mathrm{c}}\end{array}$ & $\begin{array}{r}10 \\
6 \\
8 \\
8\end{array}$ & $\begin{array}{l}5.07 \\
5.00 \\
4.93 \\
4.98\end{array}$ & $\begin{array}{l}0.11 \\
0.06 \\
0.09 \\
0.11\end{array}$ & $\begin{array}{l}0.03 \\
0.02 \\
0.03 \\
0.04\end{array}$ & $\begin{array}{l}3.16 \\
0.0403^{*} \\
\mathrm{MM}_{\mathrm{c}}: \mathrm{SN}_{\mathrm{c}}{ }^{*}\end{array}$ \\
\hline Lactose, $\mathrm{kg}$ & $\begin{array}{l}\mathrm{MM}_{\mathrm{c}} \\
\mathrm{JA}_{\mathrm{c}} \\
\mathrm{SN}_{\mathrm{c}} \\
\mathrm{DF}_{\mathrm{c}}\end{array}$ & $\begin{array}{r}10 \\
6 \\
8 \\
8\end{array}$ & $\begin{array}{l}351.88 \\
288.46 \\
296.11 \\
343.73\end{array}$ & $\begin{array}{l}54.40 \\
48.06 \\
38.67 \\
24.78\end{array}$ & $\begin{array}{r}17.20 \\
19.62 \\
13.67 \\
8.76\end{array}$ & $\begin{array}{l}4.35 \\
0.0123^{*}\end{array}$ \\
\hline Non fat solids, $\mathrm{kg}$ & $\begin{array}{l}\mathrm{MM}_{\mathrm{c}} \\
\mathrm{JA}_{\mathrm{c}} \\
\mathrm{SN}_{\mathrm{c}} \\
\mathrm{DF}_{\mathrm{c}}\end{array}$ & $\begin{array}{r}10 \\
6 \\
8 \\
8\end{array}$ & $\begin{array}{l}620.52 \\
522.58 \\
529.50 \\
611.54\end{array}$ & $\begin{array}{l}88.89 \\
81.86 \\
65.49 \\
37.27\end{array}$ & $\begin{array}{l}28.11 \\
33.42 \\
23.15 \\
13.18\end{array}$ & $\begin{array}{l}4.16 \\
0.0148^{*}\end{array}$ \\
\hline
\end{tabular}

${ }^{1}$ standard deviation of the mean; ${ }^{2}$ standard error of the mean; ${ }^{3} \mathrm{~F}$-value/P-value

$* \mathrm{P}<0.05 ; * * \mathrm{P}<0.01$

Production of milk, protein, lactose, NFS and content of fat and lactose for 305 days of lactation statistically differed according to the season of calving (Table 8). DFc and MMc cows had the highest MY, while JAc cows, the lowest. The JAc cows had the highest fat content and MMc cows, the lowest. The DFc cows produced the most protein and JAc cows the least. 
Interactions between factors

We found interactions only between the sire and feeding factors in the BW variable at 8 weeks, ADG from birth to weaning, percentage of protein and lactose in milk $(\mathrm{P}<0.05)$.

\section{DISCUSSION}

It was found that the production of milk, FCM and protein were significantly higher in the LH group than in the IH group. However, the effect of housing from the second to seventh day of life could be suppressed by the method of feeding milk to weaning. That had a decisive effect on the growth of calves and subsequent milk production. Further investigation of the relationships between feeding and growth during rearing and subsequent milk production, and between housing and growth during rearing would be desirable to analyse whether housing during rearing affects subsequent milk production.

The highest production of milk, FCM, protein, lactose, NFS and TS were in the UF group, with the lowest found in group AF. This could be explained by the higher BW at calving. According to the results of Khalili et al. (1992), calves given a high level of milk or MR in early life have a BW advantage over similar calves given a lower level of milk. Differences in BW due to increased DWG in the early life of a calf may be retained subsequently or, in certain situations, the difference in BW may increase later in life. Group UF had just this advantagethese cows had BW's that were higher by 35.7 and $18.6 \mathrm{~kg}$ in the $1^{\text {st }}$ month of lactation in comparison with groups AF and BF. This was the result of their better growth in the rearing period. This shows that rearing conditions had a long-term effect on growth until the age of calving.

Before weaning, the suckling calves (UF) grew faster than the conventionally fed calves, probably as a result of a higher milk intake. This was so even when we limited the amount of milk by changing the number of calves per cow. In suckling calves, postnatal growth rates of ad libitum-fed calves were greater than in calves fed with a limited intake (Egli and Blum, 1998).

Another reason can be the better quality of nutrition, i.e. native milk versus MR. Animals of group UF obviously received more valuable nutrition from the udder than the animals from groups AF and BF. In the work of Skrzypek et al. (2003), calves fed by whole milk up to weaning showed better growth than calves fed by MR or combination of whole milk and MR. Similarly, in the experiment of Bar-Peled et al. (1997), heifer calves that suckled milk had higher DWG, an earlier age at calving, and a tendency towards greater MY than calves fed MR. 
Calves with free access to colostrum and milk were able to digest and metabolize high amounts of feed (Hammon et al., 2002) and higher feed intake was reflected by a higher DWG.

It is probable that very early weaning from the mother (for example, in the case of our AF and BF groups) reduces adaptive abilities of calves and decreases their resistance to stress. Skrzypek et al. (2003) reported that feeding native milk could reduce the incidence of diarrhoea and this could be seen in our case of feeding from buckets or from the CCF, in particular. According to Plath et al. (1998) a higher proportion of calves reared in groups with CCF was affected by diarrhoea and bronchopneumonia and showed lower DWG than calves reared in groups with bucket feeding. The risk of developing respiratory disease was 2.8 times higher in LH with CCF than in calves kept in IH (Svensson et al., 2000).

How can we explain that cows born and calving in the autumn or winter showed the highest production of milk and its components? There is probably an effect of close relationship with BW. Calves born in the winter tended toward higher DWG than did calves born in other seasons. In contrast, calves born in the summer showed a tendency towards decreased DWG (Place et al., 1998). High temperatures during summer can lower immunity and transfer of maternal immunoglobulins to colostrum, the ability of calves to absorb immunoglobulins, and vitality of newborns.

Because the feed ration was the same throughout the year, the negative effects associated with summer are not based on forage quality. However, the effect of season on MY could be related to the changes in either temperature or photoperiod. According to Maltz et al. (2000), the summer-calving cows attained minimal BW sooner than winter-calving cows. They suppose that the negative energy balance during the summer modified the homeorhetic mechanism so that in comparison with winter-calving cows, more nutrients are diverted for repletion of body reserve on the account of their flow to the udder.

It seems that the low temperature in the winter enables a cow in the first third of lactation to express her full MY potential. Heat stress is therefore the main cause of lower MY in cows born and calving in the summer (Knizkova et al., 2000).

\section{CONCLUSIONS}

It can be concluded that in primiparous cows, growth during the liquid-feeding period, milk and its composition are affected by the housing of these cows to weaning, feeding milk or milk replacer, the sire line, and the season of birth and calving.

After calving, the animals kept from the second to seventh day of life in loose housing yielded more milk, FCM and protein than those kept in individual 
housing. The heifers fed by nursing cows had the highest production of milk, FCM, protein, lactose, NSF and TS after the first calving and the heifers fed by $\mathrm{CCF}$, the lowest.

We therefore recommend devoting more attention in practical conditions to the rearing of heifers descended from high-yielding cows by nursing cows. This method is still considered as extensive, but given the results of elevated milk production in primiparous cows, it would certainly be beneficial.

Effects of the sire were significant for DWG from birth to weaning, contents of fat, protein, lactose, NSF, TS, and yields of milk, lactose and NFS. This notable impact throughout the entire rearing period and lactation must be taken into account in sire selection.

Dairy cows born in the winter showed the highest growth to weaning and production of milk, protein, lactose, SNF and TS. Dairy cows calving in the winter and in the spring yielded the most milk, protein, lactose and SNF, while those calving in the summer, the least.

We presume that reducing the number of first-calf heifers in the summer would facilitate improving the balance of milk production in the course of the year. That means limiting the breeding of heifers in September and October and refraining from synchronizing oestrus during these months.

\section{REFERENCES}

Anonymous, 1996. Statistix for Windows. User's Manual. Analytical Software, Tallahassee (USA)

Arave C.W., Albright J. L., Armstrong D.V., Foster W.W., Larson L.L., 1992. Effects of isolation of calves on growth, behavior, and first lactation milk yield of holstein cows. J. Dairy Sci. 75, 3408-3415

Arave C.W., Mickelsen C.H., Walters J.L., 1985. Effect of early rearing experience on subsequent behavior and production of Holstein heifers. J. Dairy Sci. 68, 923-928

Bar-Peled U., Robinzon B., Maltz E., Tagari H., Folman Y., Bruckental I., Voet H., Gacitua H., Lehrer A.R., 1997. Increased weight gain and effects on production parameters of Holstein heifer calves that were allowed to suckle from birth to six weeks of age. J. Dairy Sci. 80, 2523-2528

Egli C.P., Blum J.W., 1998. Clinical, haematological, metabolic and endocrine traits during the first three months of life of suckling Simmentaler calves held in a cow-calf operation. J. Vet. Med. A 45, 99-118

Hammon H. M., Schiessler G., Nussbaum A., Blum J.W., 2002. Feed intake patterns, growth performance, and metabolic and endocrine traits in calves fed unlimited amounts of colostrum and milk by automate, starting in the neonatal period. J. Dairy Sci. 85, 3352-3362

Hayes B.J., Carrick M., Bowman P., Goddard M.E., 2003. Genotype $\times$ environment interaction for milk production of daughters of Australian dairy sires from test day records. J. Dairy Sci. 86, 3736-3744

Jones G.M., 1993. Body condition scores for evaluation of nutritional status. Virginia Technical and Virginia State University, p. 6. In: The National Dairy Database, Version 2.0, Board of Regents University of Wisconsin System, CD-ROM 
Kaczor A., 2000. Behaviour and weight gains of calves in two different housing systems. Ann. Anim. Sci. - Rocz. Nauk. Zoot. 27, 309-321

Khalili H., Crosse S., Varvikko T., 1992. The performance of crossbred dairy calves given different levels of whole milk and weaned at different ages. Anim. Prod. 54, 191-195

Knizkova I., Kunc P., Novak P., 2003. Physiological, haematological and biochemical parameters in uncooled and cooled heat-stressed dairy cows. In: J. Saltijeral (Editor). Proceedings of the XIth International Congress in Animal Hygiene. Mexico City, pp. 451-454

Krohn C.C., Foldager J., Mogensen L., 1999. Long-term effect of colostrum feeding methods on behaviour in female dairy calves. Acta Agr. Scand., Sect. A, Anim. Sci. 49, 57-64

Krzyżewski J., Strzałkowska N., Reklewski Z., Dymnicki E., Ryniewicz Z., 2004. Influence of calving interval length in HF cows on milk yield, its composition and some reproduction traits. Med. wet. 60, 76-79

Maltz E., Kroll O., Barash H., Shamy A., Silanikove N., 2000. Lactation and body weight of dairy cows: interrelationships among heat stress, calving season and milk yield. J. Anim. Feed Sci. 9, 33-45

Metz-Stefanowska J., 1987. Productivity aspects of keeping dairy cow and calf together in the postpartum period. Livest. Prod. Sci. 16, 385-394

Niwińska B., Strzetelski J.A., 2004. Effects of type of liquid feed and feeding frequency on calf performance. J. Anim. Feed Sci. 13, Suppl. 1, 167-170

Petrikovic P., Sommer A., 2002. Requirement of Nutrients for Cattle. Publication of VUZV, Nitra, $2^{\text {nd }}$ Issue, pp. 62

Place N.T., Heinrichs A.J., Erb H.N., 1998. The effects of disease, management, and nutrition on average daily gain of dairy heifers from birth to four months. J. Dairy Sci. 81, 1004-1009

Plath U., Knierim U., Schmidt T., Buchenauer D., Hartung J., 1998. Gruppenhaltung über zwei bis acht Wochen alter Mastkälber. Deut. Tierärztl. Wochenschr. 105, 81-136

Shearer J.K., Beede D.K., 1990. Effects of high environmental temperature on production, reproduction, and health of dairy cattle. Agr. - Pract. 11 (5), 20-27

Skrzypek R., Osięgłowski S., Hofmański D., 2003. Biological and economic evaluation of milk replacers for calves. Ann. Anim. Sci. 3, 127-136

Snedecor G.W., Cochran W.G., 1989. Statistical Methods. The Iowa State University Press. Ames, Iowa

Strzetelski J., Niwińska B., Kowalczyk J., Jurkiewicz A., 2001. Effect of milk replacer feeding frequency and level on concentrate intake and rearing performance of calves. J. Anim. Feed Sci. $10,413-420$

Svensson C., Emanuelson U., Petterson K., 2000. Health status of dairy calves kept in individual pens or in group pens with or without automatic milk feeder. In: M.J.M. Tielen, M.Th. Voets (Editor). Procedings of $\mathrm{X}^{\text {th }}$ International Congress on Animal Hygiene. Maastricht (The Netherlands), pp. 426-430

Tancin V., 1991. The effect of season on the thyroid hormones and insuline levels in blood serum of calves. Živoć. Vyr. 36, 849-856

Vaarst M., Jensen M.B., Sandager A.M., 2001. Behaviour of calves at introduction to nurse cows after the colostrum period. Appl. Anim. Behav. Sci. 73, 27-33 


\section{STRESZCZENIE}

Wpływ czynników środowiskowych i pochodzenia na wydajność i skład mleka krów w pierwszej laktacji

Celem pracy było zbadanie czy na wydajność mleka (MY) pierwiastek wpływa sposób ich utrzymania do odsadzenia, metoda żywienia dietą płynną, linia ojcowska, sezon urodzenia i wycielenia. Spośród 32 jałówek, od 2-go dnia życia 19 utrzymywano indywidualnie (IH), a 13 w pomieszczeniu wolnostanowiskowym (LH). W 7 -ym dniu życia cielęta IH podzielono na 2 grupy: 10 jałówek umieszczono w kojcu z automatycznym podawaniem preparatu mlekozastępczego (AF), 9 - otrzymywało mleko $\mathrm{z}$ wiader (BF). Jałówki z grupy LH były odchowywane przez krowy mamki (UF).

Po wycieleniu pierwiastki były utrzymywane w oborze wolnowybiegowej. W ciagu pierwszych 8 miesięcy laktacji krowy-pierwiastki $\mathrm{z}$ grupy LH wyprodukowały więcej mleka, a w ciągu 305 dniowej laktacji więcej mleka, FCM i białka $(\mathrm{P}<0,05)$. W pierwszej laktacji największą MY i FCM osiagnęły krowy UF $(6894,1$ i 6541,9 kg), najniższą krowy AF $(5757,5$ i 5820,9 kg; P<0,01).

Zawartość tłuszczu oraz s.m. (TS) w mleku była największa u krów AF. Wystapiły różnice w zawartości tłuszczu, białka, laktozy, s.m. beztłuszczowej, TS oraz MY w zależności od pochodzenia krów. MY:FCM były niższe u krów urodzonych i wycielonych latem, najwyższe u krów urodzonych i wycielonych zimą i wiosną. 